Florida International University FIU Digital Commons

FIU Electronic Theses and Dissertations

University Graduate School

7-2-1997

\title{
The lived experience of healing touch with cancer patients
}

Charlene Ann Christiano

Florida International University

DOI: 10.25148 /etd.FI14060824

Follow this and additional works at: https://digitalcommons.fiu.edu/etd

Part of the Nursing Commons

\section{Recommended Citation}

Christiano, Charlene Ann, "The lived experience of healing touch with cancer patients" (1997). FIU Electronic Theses and Dissertations. 2354.

https://digitalcommons.fiu.edu/etd/2354

This work is brought to you for free and open access by the University Graduate School at FIU Digital Commons. It has been accepted for inclusion in FIU Electronic Theses and Dissertations by an authorized administrator of FIU Digital Commons. For more information, please contact dcc@fiu.edu. 
ELORIDA INTERNATIONAL UNIVERSITY

$$
\text { Miami, Florida }
$$

THE LIVED EXPERIENCE OF HEALING TOUCH

WITH CANCER PATIENTS
A thesis submitted in partial satisfaction of the requirements for the degree of
MASTER OF SCIENCE
IN
NURSING
by

Charlene Ann Christiano 
To: Linda A. Simunek

School of Nursing

This thesis, written by Charlene Ann Christiano, and entitled THE LIVED EXPERIENCE OF HEALING TOUCH WITH CANCER PATIENTS, having been approved in respect to style and intellectual content, is referred to you for judgement.

We have read this thesis and recommend that it be approved.

Cynthia Fletcher

Marilyn A. Ray

Jacquelyn Hartley

Major Professor

Date of Defense: July 22, 1997

The thesis of Charlene Ann Christiano is approved.

Dean Linda A. Simunek

School of Nursing

Dr. Richard L. Campoell

Dean of Graduate Studies

Florida International University, 1997 
OCOPYRIGHT 1997 by Charlene Ann Christiano

All rights reserved

iii 
I dedicate this thesis to my husband, Charles, and my son, Daniel. If not for their love, understanding and patience, this work could not have been completed. In addition, I dedicate this to all the healers of the world. May they continue their works for the benefit of all. 


\section{ACKNOWLEDGEMENTS}

I wish to thank the members of my committee for their guidance, wisdom, and patience. A very special thank you must go to Dr. Ray, for without her method, support, compassion, and encouragement, this thesis would not have the depth that it does. I will cherish her assistance, mentoring, and friendship always.

I would like to thank Dr. Fletcher for her persistence when my patience was running thin. She helped me see what others may not.

And to my major professor, Dr. Hartley, I thank her for her support and confidence in my completing this thesis.

I also would like to thank Dolores Krieger and Janet Mentgen for their pioneering work in energy healing. If not for them, this ancient healing modality would still be virtually unknown to us. 
ABSTRACT OE THE THESIS

THE LIVED EXPERIENCE OF HEALING TOUCH

WITH CANCER PATIENTS

by

Charlene Ann Christiano

Florida International University, 1997

Miami, Florida

Professor Jacquelyn Hartley, Major Professor

The recent use of complementary therapies by cancer patients has prompted the study of the use of Healing Touch, an energy based therapy, to learn the meaning of the experience. By using Ray's Caring Inquiry, a phenomenologichermeneutic process, the lived experience of receiving Healing Touch was elicited from three cancer patients. Through the interactions of the Healing Touch practitioners, the cancer patient participants, and the energy in and around them, specific themes were expressed: body-physical, emotion-feeling, mental-knowing, and spirit-essence. Further abstracting lead to the metathemes sensation and perception. Through a change in consciousness, a oneness/wholeness was experienced. The unity of meaning elicited was the Rhythm of Oneness Through Energy which is the connecting, opening, and cocreating through caring, the wholeness of each to become one through rhythms of energy. 


\section{TABLE OE CONTENTS}

CHAPTER

PAGE

I. INTRODUCTION $\ldots \ldots \ldots \ldots \ldots \ldots \ldots \ldots \ldots \ldots$

Healing Touch $\ldots \ldots \ldots \ldots \ldots \ldots \ldots \ldots \ldots \ldots \ldots \ldots \ldots$

Energy Fields ..................

Layers of the Energy Fields $\ldots \ldots \ldots \ldots \ldots$

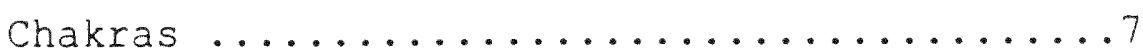

Relationship Between Energy Layers

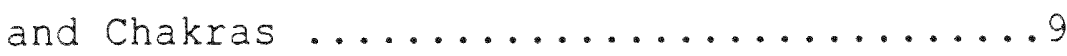

Purpose $\ldots \ldots \ldots \ldots \ldots \ldots \ldots \ldots \ldots \ldots \ldots \ldots \ldots$

Research Question .....................

Significance $\ldots \ldots \ldots \ldots \ldots \ldots \ldots \ldots \ldots \ldots \ldots \ldots$

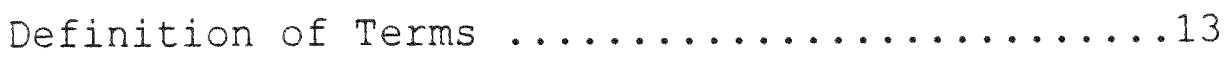

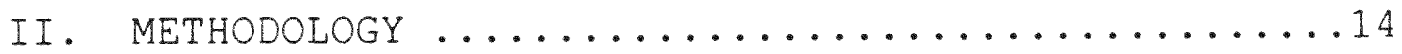

Philosophical Eoundation of Caring Inquiry ....14

Hermeneutics $\ldots \ldots \ldots \ldots \ldots \ldots \ldots \ldots$

Humanistic Caring ..................

Caring Inquiry .......................

The Caring Inquiry Process for the Study of

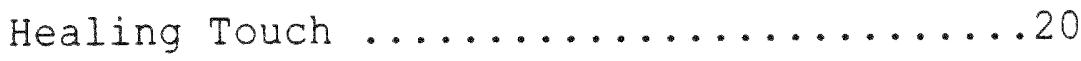

Data Generation .....................20

Sample and Setting ................20

Ethics of the Research ............22

Compassionate "we" ................23 
Observational and Dialogical Generation

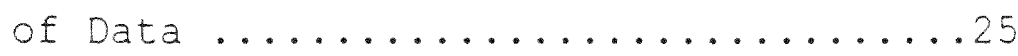

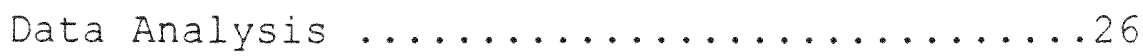

Theory of Meaning ..................

Dialoguing with written Texts ..........28

Credibility and Significance ..........28

III. ANALYSIS AND RESULTS OE THE DATA ............. 30

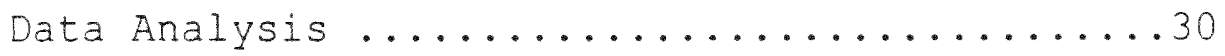

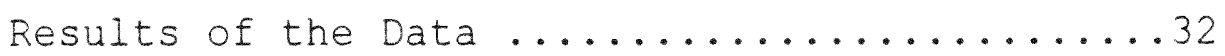

Interactions $\ldots \ldots \ldots \ldots \ldots \ldots \ldots \ldots \ldots \ldots \ldots \ldots$

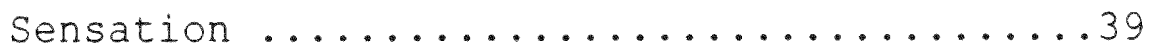

Perception ......................

Change in Consciousness ............43

Rhythm of Oneness Through Energy .......44

IV. IIteratuRE REVIEW .................

Nursing Literature $\ldots \ldots \ldots \ldots \ldots \ldots \ldots \ldots$

Nursing Theory ..................... 49

Philosophy $\ldots \ldots \ldots \ldots \ldots \ldots \ldots \ldots \ldots \ldots \ldots \ldots \ldots \ldots \ldots \ldots \ldots \ldots$

V. DISCUSSION $\ldots \ldots \ldots \ldots \ldots \ldots \ldots \ldots \ldots \ldots \ldots \ldots \ldots \ldots \ldots \ldots \ldots \ldots$

Implications for Nursing .............

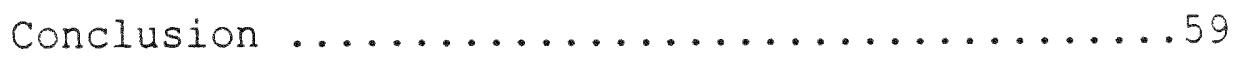

LIST OE REEERENCES $\ldots \ldots \ldots \ldots \ldots \ldots \ldots \ldots \ldots \ldots \ldots \ldots \ldots \ldots \ldots$

APPENDIXES $\ldots \ldots \ldots \ldots \ldots \ldots \ldots \ldots \ldots \ldots \ldots \ldots \ldots \ldots \ldots \ldots \ldots \ldots \ldots \ldots \ldots$

A. Techniques Used in Healing Touch ..........67

B. Informed Consent .....................

C. General Information Sheets ............. 82 
D. Healing Touch Methods Used During

the Encounter $\ldots \ldots \ldots \ldots \ldots \ldots . \ldots \ldots$ 


\section{LIST OE TABLES}

TABLE

PAGE

1. Healing Touch Methods Used ...............24

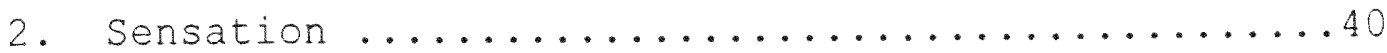

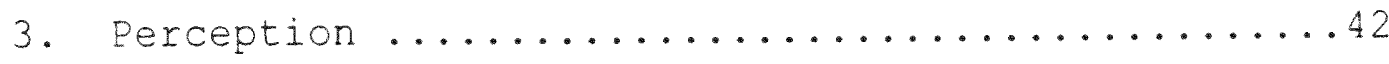




\section{IIST OE EIGURES}

EIGURES

PAGE

1. Rhythm of Oneness Through Energy ............33 
Chapter 1

Introduction

Militions of people each year are diagnosed with some form of cancer (Parker, Tong, Bolden, \& Wingo, 1996). Coping and living with this disease has been an important concern for health practitioners as well as for patients for many years (Ferrell, Dow, Leigh, Ly, \& Gulasekaram 1995; Northouse, 1995; Stearns \& Whedon, 1993; Zacharias, Gilg, \& Eoxall, 1994). To assist in coping and improving quality of life for cancer patients, different types of interventions have been attempted with varying degrees of success (Montbriand, 1993; Owens \& Ehrenreich, 1991). Patients have begun turning to complementary treatment modalities, such as visual imagery, massage therapy, and music therapy as part of their therapeutic milieu (Beck, 1991; Ferrell-Torry \& Glick, 1993; Johnston \& Rohaly-Davis, 1996; Montbriand, 1993). According to Dossey (1995), alternative (complementary) therapies have probably existed throughout the history of humankind and that it is natural for humans to seek other methods of healing.

Energy based therapies, such as Therapeutic Touch and Healing Touch, have gained prominence in the last several years as complementary therapies and are now being taught, studied, or both at universities and institutions throughout the United States (Hover-Kramer, 1996c; Bronstein, 1996; Miller, 1996). In fact, the United States Congress 
established the Office of Alternative Medicine within the National Institutes of Health to study nontraditional methods of healing (Hover-Kramer, 1996c; Dossey, 1995; Ernst, 1993). By lending credibility to the existence of nontraditional therapies and the current research in progress to ascertain the effectiveness of those in question, nursing research on Healing Touch is necessary to assist in adding to the body of knowledge which is forthcoming. Healing Touch

Healing Touch, a program of energy therapy as well as a philosophy of care, was developed by Mentgen (Mentgen \& Bulbrook, 1994) as an energy based approach to healing. It involves the use of a Higher Power or the Universal Energy Field around us to assist the individual in the self healing of the body-emotion-mind-spirit components. By attempting to restore the wholeness of the person, the Healing Touch practitioner hopes to facilitate harmony and balance. In doing so, the individual is able to utilize the energy to heal themselves.

Mentgen had been utilizing this unique healing modality for many years prior to developing a formal program. Through her experience with other worldwide healers, as well as through meditation, she identified, modified, or both the specific techniques of Healing Touch. She affiliated with the American Holistic Nurses' Association to develop this 
innovative program and philosophy to teach others in the national and international community (Mentgen \& Bulbrook, 1994). The multilevel educational and self-growth processes needed by the practitioner allow for the Healing Touch relationship, its techniques, and the philosophy to become deeply ingrained, thereby, enhancing the ability of the healer.

Healing Touch (HT) has its base in Therapeutic Touch, which was developed by Krieger (1979), as well as other healing modalities (Hover-Kramer, 1996e). Therapeutic Touch (TT) consists of five steps: centering, assessing, unruffling, modulation of energy, and closure or stopping (see Appendix A). TT is a method based on laying of the hands "to direct human energies to help or heal someone who is ill" (Krieger, 1979, p. 1). One of the differences between TT and HT is that with TT, the healer consciously directs his/her excess energy to assist the healee; whereas with HT the healer aligns himself/herself with a Higher Power or the Universal Energy Eield to transfer energy (Krieger, 1979; Hover-Kramer, 1996d). By aligning oneself with a higher power, the healer does not drain his/her own energy field.

Another difference between TT and HT is that Healing Touch is comprised of many specifically named techniques (see Appendix A) which may be utilized exactly as identified or may be modified depending on the intuition of the healer. 
True intuition, according to Hover-Kramer (1996a), "is the function of a person who has developed higher levels of consciousness..." (p. 78). By perceiving and acknowledging this intuition, the healer can then know which technique to use or where to place the hands. The techniques done are to assist the person to self-heal and to create wellness by repatterning the person's energy fields and energizing the chakras. It is through the energy fields and the chakras that the status of health is made known to the healer. By doing specific techniques, harmony and balance are restored to the energy fields and the chakras to place the person in the best position to heal.

Energy fields. Many of the processes of the human body are energy dependent, such as cardiac function, nerve impulse, cellular metabolism, and the electrotonic conduction of the rods and cones in the eye (Guyton, 1987). Energy permeates the entire being as well as the environment in which it lives. The body and its surroundings are interconnected and considered to be energy fields not have energy fields (Hover-Kramer, 1996d). It is on this basis that Brennan (1987), Bruyere (1994), Krieger (1979), Mentgen (Mentgen \& Bulbrook, 1994, 1995), and many others formulated their energy therapies.

One of the oldest forms of healing is using energy or its principles (Scandrett-Hibdon, 1996). Knowledge of energy can be found as far back as 5,000 years ago in Egypt 
(Scandrett-Hibdon, 1996). In ancient Indian tradition, the belief of prana was widespread as the universal energy, the basic element and source of life. Yogis manipulated this prana to maintain altered consciousness and youth. The Chinese held the belief of $\mathrm{Ch}$ 'i and the universal energy which pervades all living and nonliving things. These are a few of the many cultures which used energy in healing (Brennan, 1987).

Many scientists over the centuries have studied energy fields. In the 1800s, Maxwell and Von Reichenbach examined the "odic" force, or field, which was similar to electromagnetic fields. They found this field to have its own unique polarity (Brennan, 1987).

In the early 1900s, Kilner studied the Human Energy Field through screens and filters. He found layers of color, called "aura", which were different between individuals, as well as with age, mentality and illness. He categorized a diagnostic list of colors dependent on the condition (Brennan, 1987).

In the mid 1900s, De La Warr and Drown (as cited in Brennan, 1987) built instruments to detect radiation from living things. By the use of photographs, they were able to show internal formations of many diseases, such as tumors, cysts, and tuberculosis. At this same time, Reich observed pulsating energy around every animate and inanimate object he studied. He called this energy "orgone" (Brennan, 1987). 
More recently, Motoyama (as cited in Brennan, 1987) measured low light levels from those practicing yoga for many years using a low-light movie camera in a darkroom. More significant is the work of Hunt las cited in Brennan, 1987) who measured the frequency of low voltage signals from the skin of healers by the use of silver/silver chloride electrodes. She was able to observe the aura, describe its colors and mathematically derive frequencies for the colors based on wave forms.

A method by which to see the aura is by Kirlian photography. This special method of photography allows for the actual visualization of the multiple layers of energy surrounding the human body or other inanimate objects (Moss, 1979). Stanwick (1996) noted that further research is needed for the use of Kirlian photography for diagnostic purposes. Layers of the energy fields. Mentgen incorporated much of Brennan's (1987) view of the body having seven layers of energy fields. These layers are interactive and arranged in an hierarchical manner extending outward from each other (Brennan, 1987; Gerber, 1996; Hover-Kramer, 1996d). Each layer has a different frequency, or vibration, with the slowest vibration closest to the body and the highest vibration furthest from the body. The vibration becomes important in the healing of the person since the Healing Touch practitioner must align his/her own vibration accordingly. The seven layers are the etheric body, the 
emotional body, the mental body, the astral body, the etheric template, the celestial body, and the ketheric template (Brennan, 1987; Gerber, 1996; Hover-Kramer, 1996d). Although often discussed as distinct layers, they are actually superimposed on each other due to the physics' principle that energy of differing frequencies can coexist in the same space without the destruction of the other (Gerber, 1996).

Chakras. Ancient Eastern philosophy and medicine identified chakras as important components of healing and wellness (Bruyere, 1994). Chakras are energy vortices, called "wheels of life" in Sanskrit (Brennan, 1987; Bruyere, 1994). They are involved in taking energy from higher frequencies from the energy fields and changing it to a form the body can use. The energy is transmitted along yet identified energetic channels to affect the body as a whole. The exact mechanism of this is not understood (Gerber, 1996). There are seven main chakras and each has its own color, which itself is an energy frequency in visual form. These chakras are located over specific parts of the body with names that correspond appropriately to the nerve plexes and organ systems of the physical body. The root, or base, chakra is the first chakra located at the base of the spine and radiates downward from the perineum. The color it is associated with is red. The underlying function relates to the lower parts of the body, the functions of movement 
and elimination, the sense of security, being grounded, the will to live and/or enjoy life, and to survive, as well as enthusiasm, joy, and vitality (Hover-Kramer, 1996b).

The second chakra, or sacral chakra, is located just below the umbilicus and is associated with the color orange. This chakra deals with emotions, clear thinking, and sexuality. It is associated with the reproductive and sexuality glands, body fluid balance, and nutritional absorption. It also relates to the expressions of sexuality and relationship issues (Brennan, 1987; Hover-Kramer, $1996 b)$.

The third chakra, or solar plexus chakra, is associated with power, ego, and control. The associated color is yellow. This chakra is located at the solar plexus at the base of the sternum and relates to the digestive organs. It is associated with being able to complete something from start to finish (Brennan, 1987; Gerber, 1996; Hover-Kramer, 1996b).

The heart chakra, or the fourth, is located over the heart mid-sternally. The associated color is green, the color of life. The associated organs are the thymus, respiratory and cardiovascular systems. This is our center to love ourselves and the will to love others, forgiveness, and acceptance of love. It is often designated one's transformative center. It is at the heart center where the seat of emotions of love is found. The love is pure, a 
spiritual caring for self and others (Hover-Kramer, 1996b).

The throat chakra, or the fifth, is located in the middle of the neck. The color of the throat chakra is light blue or turquoise. The associated organs are the neck, thyroid, throat, esophagus, and the functions of speech and sound. This chakra is the location of perceptions of the self, responsibility, and communication (Brennan, 1987; Hover-Kramer, 1996b).

The sixth chakra, or brow, is located in the middle of the forehead and often called the "third eye." This chakra relates to the pituitary gland, brain, eyes, ears, head, and nose. It is the color of deep indigo. This area is the focus of insight, self-identity, intuition, wisdom, compassion for others, high level thinking, and sensory perception (Brennan, 1987; Hover-Kramer, 1996b).

The seventh, or crown chakra, is located on the middle of the head and expands upward. It is known as the spiritual center where integration of the whole person with the universe occurs. As the highest energy vortex, it is connected with the Higher Fower. At this center, qualities of openness and expansiveness occur. It is the seat of the soul-conscious. It has a variety of colors such as white, lavender, or purple (Brennan, 1987; Hover-Kramer, 1996b).

Relationship between energy layers and chakras. The chakras, as spinning, cone-shaped energy vortices, interconnect with all the layers of the energy field from 
lower energy frequencies to higher energy frequencies. The tip, or nadis, of each chakra meets along a central energy channel which runs parallel to the spinal cord vertically. The second through sixth chakras extend both anteriorly and posteriorly, with the first extending inferiorly and the crown extending superiorly, through all the layers of the energy field. Energy can be received from outward into the body and vice versus through this system of energy flow between the chakras and the energy fields; thus, creating a multidimensional flow of energy (Brennan, 1987; Gerber, 1996; Hover-Kramer, 1996b).

An imbalance or blockage of energy can occur in any layer, chakra or both. The manifestations can reveal themselves on the physical (or body), emotional, mental, or spiritual levels. The Healing Touch practitioner, through intuition and perception, is able to locate and identify with his/her senses of touch, hearing, sight, smell, and emotions, the imbalance or blockage in the energy layers, chakras, or both. These may be sensations of temperature, texture, movement, density, disruptions, colors, sounds, odors, or feelings. Often times, these occur simultaneously (Hover-Kramer, 1996b, 1996d). According to Hover-Kramer, "whatever means of assessment are used, the hands of the healer are the tools. The compassion of the healer is the perceiver. The mind of the healer is the interpreter. And the spirit or soul of the healer is the guide" (1996, p.80). 


\section{Purpose}

Coping and living with cancer is a significant problem and the use of complementary therapies by cancer patients has increased. Therefore, it is important to explore the use of Healing Touch in cancer patients as a complementary therapy by investigating the lived experience by a Caring Inquiry process, which utilizes the phenomenologichermeneutic (descriptive and interpretive) approach, as well as the human caring perspective.

Because the relationship between the Healing Touch practitioner and the cancer patient during the encounter results in the compassionate "we", Caring Inquiry is used to elicit an understanding of the meaning of the experience. Although the encounter is a mutually significant moment for each as a human mode of caring, the study was done to elicit the meaning of the experience of receiving Healing Touch by the patient's standpoint only. Research Question

In keeping with the Caring Inquiry, the following research question was set forth in an attempt to understand the experience of Healing Touch as a complementary therapy as well as to increase the knowledge of this modality: "What is the meaning of the experience of receiving Healing Touch?"

More specifically, the question to the cancer patients was, 'what is the meaning of receiving Healing Touch to 
you?' Dependent on the answer, other broad questions were asked to further elicit the meaning. In asking as such, the researcher elicited both information about the meaning of the experience and received a description of what the Healing Touch experience felt like to the cancer patient. Significance

Inquiry into the lived experience of receiving Healing Touch was necessary to provide information as to the effects of the treatment as well as to increase understanding of this often misunderstood treatment modality. Therefore, the question posed was 'What is the meaning of the experience of Healing Touch to you as the patient with cancer?'

The significance of this research was to explore the use of Healing Touch as a complementary therapy and to establish a base of research for Healing Touch through qualitative methods. Healing Touch was shown to have an important impact on the individual's cancer experience. By utilizing Healing Touch as a complementary therapy, cancer patients were able to identify another modality to use in addition to other therapies needed to assist them in the everyday struggle to live and survive.

For nursing practice, Healing Touch provided a more holistic, compassionate method of the provision of care to supplement the technocratic methods currently used. It is hoped that Healing Touch may bring nursing back to its original intent, caring for the whole person. 
This research revealed how the use of Caring Inquiry elicited the meanings of relationships between two or more entities, how the human mode of caring is necessary to treat the whole of the individual in the form of the compassionate "we", and how the presence of one affects the other mutually and inclusively. In addition, the study provided a strong base of knowledge for further research on Healing Touch. Definition of Terms

1. Healing Touch - is a philosophy of care using energy based therapeutic interventions which help in maintaining wellness or assist in the treatment of illness and disease, and encourage self-healing by addressing the whole person body-emotion-mind-spirit (Mentgen \& Bulbrook, 1994, 1995). 2. Therapeutic Touch - an energy based technique, developed by Krieger (1979), derived from laying of the hands which directs human energy to the body to assist one in attaining and/or maintaining health and/or treatment of illness and disease. It consists of a series of five steps: centering, assessing, unruffing, and modulation of energy, and stopping.

3. Body-emotion-mind-spirit - the term used to describe the totality of humanness.

4. Intuition - a personal way of knowing something, often without identifiable information leading to that knowledge. 5. Healing Touch techniques - are a number of techniques used by the Healing Touch practitioner (see Appendix A). 


\section{Chapter 2}

\section{Methodology}

In order to study the lived experience of Healing Touch, one must first consider the philosophical basis of care, the meaning of being, and human caring theories. These lay the foundation to the Caring Inquiry process utilized in this research. By holding the literature review in abeyance until after the data was collected and analyzed (described and interpreted), the researcher was able to set aside any previous knowledge about caring and Healing Touch in order to elicit a pure understanding of the phenomenon. Philosophical Foundation of Caring Inquiry

Husserl is considered to be the father of phenomenology (Stapleton, 1983). He stated that philosophy was a rigorous science and that phenomenology would be the basis for all science and philosophy (Streubert \& Carpenter, 1995). He felt that philosophy aspired to be the allencompassing, justifiable knowledge of all that is (Kockelmans, 1967). Thus, from a philosophical standpoint, phenomenology is defined as "being 'first' philosophy and to provide the means for all the rational criticism that needs to be performed..." (Husserl, 1962, p. 172). This rational criticism is not the same as scientific reduction, but more reasonably a structured reflection of the lived experience elicited.

The methodological aspect of phenomenology, in looking 
at the lived experience, uses three concepts: essences, intuiting, and phenomenological reduction. Essences are those elements which are basic to understanding phenomena and provide us with concepts. In effect, essences provide us the true, intimate meaning of some phenomenon (Husserl, 1962).

Intuition, according to Husserl, is a source of knowledge which aids us in the description of the essences experienced by others (Husserl, 1962). Intuiting is the illumination of the essences and describes the phenomena in a comprehensible form. This intuiting results in an elementary revelation of the phenomena. When intuiting, the researcher dwells with the data obtained, and it is "simply to be accepted as it gives itself out to be, though only within the limits in which it then presents itself" (Husserl, 1962, p.83).

Phenomenological (transcendental) reduction is the process of returning to the original awareness (consciousness) of the pure description. In returning, however, one must use bracketing (or epoché) to hold in temporary abeyance any preconceived notions or ideas (presuppositions) of the phenomenon. In doing so, one remains pure to the acquired information and is able to intuit an illumination of the meaning of the data as expressed in the experience. In addition, bracketing helps prevent the interference of bias (Husserl, 1962). 
In transcendental reduction, "the subject becomes thematically aware of itself" (Stapleton, 1983, p.88), both "in" the world as well as "of" the world. By bracketing, the objective world is taken as simply existing and is replaced with the world "as meant" in consciousness. Thus, consciousness is a realm of absolute being (Ray, 1994). In relation to this absolute, Husserl views one as "Being of the World" (Husserl, 1962).

Hermeneutics. A significant critic of Husserlian phenomenology, Heidegger reconstructed phenomenology in relation to hermeneutics or as an interpretive human science. His view of phenomenology is a process that allows "that which of its own accord manifests itself, reveal itself as it is" (Kockelmans, 1990, p.31). In contrast to Husserl's view of phenomenology, Heidegger rejected transcendental reduction and the bracketing of self. Heidegger stated that presuppositions need to be uncovered, not "eliminated or suspended, but are what constitute the possibility of intelligibility or meaning" (Ray, 1994, p. 120). In doing so, Heidegger moved away from transcendental reduction to an ontological idea which is "made possible by the prior understanding of 'Being in the world' (Dasein), rather than of the world" (Ray, 1994, p. 121).

Dasein, or the possibilities of Being in the world, is "characterized by its understanding of Being, the meaning of Being can only be interpreted from within this pre-current 
understanding" (Bleicher, 1980, p. 100). By understanding the meaning of Being then one can make sense of the "what is" of entities (Bleicher, 1980).

In addition, Dasein is finite transcendence of Being of which transcendence is care (Sorge) (Kockelmans, 1990). Care is found in time (temporality) and is the fundamental structure of Dasein's Being itself. As such, care is before every attitude and situation as well as with them. Therefore, care is ahead of, along with, and already in the individual (Kockelmans, 1990).

Humanistic caring. The concept of caring has been investigated by nursing scholars for many years (Boykin \& Schoenhofer, 1993). It was originally identified by Nightingale (1859) whereby the nurse cares by placing the patient in the best possible state for nature to aid in the reparative process. Her idea of care was the pursuit of nursing proper whereby the nurse performed certain tasks correctly and behaved in a specific manner.

Caring was later pursued by Leininger (1984) who identified caring as the unifying domain for the knowledge and practice of nursing as well as the essence of nursing. She viewed human caring as a universal phenomenon which was culturally dictated by the environmental, physical, psychological, social, and cultural constructs of the community (Cohen, 1991).

Watson (1988) defined caring as "the moral ideal of 
nursing whereby the end is protection, enhancement, and preservation of human dignity. Human caring involves values, a will and a commitment to care, knowledge, caring actions, and consequences" (p. 29). She identified three components of caring: nursing as both a science and an art, the existence of a mutuality of patient/nurse or intersubjectivity, and human caring is a moral ideal. These notions comprise the interaction, transaction, and transcendence of health-illness, environment, and the universe (Watson, 1988).

Boykin and Schoenhofer's (1993) theory of Nursing as Caring is based on the premise that all humans are caring and throughout life each is able to learn to express caring. The core to their theory is the view that "it is knowing the person as living caring and growing in caring..." (Boykin \& Schoenhofer, 1993, p.4) which is done moment to moment through authentic presence, always unfolding. This is experienced through the nursing situation whereby the lived experience is shared by the nurse and the nursed (Boykin \& Schoenhofer, 1993).

Roach (1992) viewed caring as a human mode of being or manifestation of being: to be is to care. This is in line with Heidegger's Being-in-the-World and that "man's essential relation to the world is one of care" (Roach, 1992, p. 13). She identified caring as the core of nursing but not unique to nursing. Roach named the five C's which 
are attributes to caring. They include compassion, competence, confidence, conscience, and commitment.

Many of the nursing theorists utilized philosophical foundations in their theories on caring, but did not address them specifically. Phenomenology and hermeneutics were not used in all of the above mentioned theories. Yet, the underlying concept of caring as a human science permeated throughout irregardless of its philosophical base. In keeping with a humanistic caring mode, Caring Inquiry incorporated underlying themes from nursing caring theories as well as the philosophies of Husserl and Heidegger.

\section{Caring Inquiry}

The use of phenomenology as both method and philosophy can only lead to the use of a method which incorporates each. Ray's Caring Inquiry is a phenomenologic-hermeneutic method which permits incorporating Husserl's view of intuition within the analytical process (description) as well as incorporating hermeneutics or interpretation with an esthetic (creative) knowing. By utilizing this method, the researcher is able to study the experience of the life-world of the other. The esthetic knowing allows the "describing and understanding [of] the meaning of being and becoming through caring" (Ray, 1991, p. 183).

Ray's methodology is not a linear process, but the processes are interwoven to allow full expression of the essence (Ray, 1990). It is a "dynamic, disciplined, 
dialectical, reflective, and creative approach..." (Ray, 1991, p. 184). By the use of the compassionate "we", or the recognition of the impact of each other's being on the other, the researcher is able to coparticipate in the encounter within the human caring perspective (Ray, 1991). The Caring Inquiry Process for the study of Healing Touch

The Intentionality of Inner Being of the Researcher is the first step in the process (Ray, 1991). The researcher reflects on self as self in a caring manner. As the meaning unfolds, the researcher will then focus on and identify presuppositions of Healing Touch and bracket them to hold in abeyance any presuppositions about Healing Touch. Data Generation

The Process of Dialogic Experiencing is the second step of Caring Inquiry. It includes selection of the participants, discussion of ethical considerations, recognition of the compassionate "we", and observational and dialogical generation of data (Ray, 1991).

Sample and setting. A sample population of three adult cancer patients, aged 18 years or older, was obtained by a purposeful sampling process referred from the social service department at a local comprehensive cancer center. No restrictions as to sex, type of cancer, metastatic disease or treatment modalities were made, however, all were English speaking. None of the sample had received any type of energy healing in the past. One had received acupuncture but did 
not equate that with energy therapy. The purpose of the minimal restraints on the selection of the sample was to provide a varied population which is more representative of the overall population of cancer patients. In doing so, it allowed a more naturalistic sampling with one common element, cancer. By restricting the sample to those who had not received energy work previously, the information obtained provided a less biased response.

All cancer patient participants were female, Jewish, aged 45-56 years, and had some college education. Two had breast cancer without metastasis and the other had leiomyosarcoma with metastasis to the lungs. Diagnosis time ranged from 10-27 months. All three had surgery for their cancers. One was receiving chemotherapy, one was on hormone therapy, and the other was not undergoing treatment. All experienced imagery and meditation, two utilized chiropractic treatments and vitamin therapy, and one used massage and acupuncture.

The Healing Touch practitioner sampling was restricted to three adult practitioners, aged 18 years or older, who had completed at least the first section of the third level within the Healing Touch educational program. The practitioners were English speaking and had at least 2 years experience with Healing Touch. The convenience sample of practitioners was obtained from a Certified Healing Touch Instructor in the immediate area. No restriction was made in 
terms of those who had worked with cancer patients previously.

The Healing Touch practitioners were all female, aged 43-56 years. Two were protestant and one catholic. Two were nurses and one was a counselor. Two of the healers had completed level IIIA and one was a certified instructor for Healing Touch. Years of practice experience ranged from 22 months to 6 years. Only one had worked with cancer patients previously.

The location of the Healing Touch session was in the cancer patients' home. This setting provided a naturalistic environment which was conducive to providing a more rich experience. The cancer patients and the Healing Touch practitioners were paired according to the time of agreement to participate; that is, the first each of the cancer patients and Healing Touch practitioners identified were paired together, the second to the second, and so on until all three pairs had been matched. The first Healing Touch practitioner had to withdraw from the study before the session was done due to a time conflict. A new Healing Touch practitioner was identified and was paired with the first participant.

Ethics of the research. All subjects invited agreed to participate in the study. Each participant was given a written consent which explained the purpose of the study, its benefits and risks, and how the encounter would occur 
(see Appendix B). The researcher assured all participants of the confidentiality and anonymity of the information collected, as well as the right to withdraw from the study at any time. After the researcher answered any questions regarding the study and provided explanations to the participants' satisfaction, all participants signed their informed consent. Demographic data forms were filled out and a time arranged for the Healing Touch sessions (see Appendix C) .

Compassionate "we". On the day of the scheduled session, the researcher met the Healing Touch practitioner at the cancer patient's home at a prearranged time. A brief introduction and a reexplanation of the session was given. The Healing Touch practitioner was only told that the patient had cancer, however, no other information was given. The cancer patient was instructed not to divulge any information regarding the specifics of her disease. The Healing Touch practitioner interacted with the participant and performed intuitively-decided techniques ranging from 30-52 minutes based upon the practitioner's findings. The researcher was present both as a caring observer as well as coparticipant in the Healing Touch experience.

The Healing Touch modalities used were varied with the exception of the use of Chakra Connection (see Table 1). Two used this modality as taught and the other modified it. No explanation was given as to why this technique was used on 
Table 1

Healing Touch Methods Used

Cancer Patient Participant

Method

1

2

3

Therapeutic Touch

As taught

$\mathrm{X}$

Modified

Chakra Connection

As taught

Modified

$\mathrm{X}$

$\mathrm{X}$

$x$

Ultrasound

As taught

$x$

Modified

Mind Clearing (lying down)

As taught

$\mathrm{X}$

Modified

Spiral Meditation

As taught

$\mathrm{X}$

Modified

Sealing a wound

As taught

X

Modified

Etheric Unruffling

As taught

Modified

X

Lymphatic Drain

As taught

Modified

$\mathrm{X}$

Note. These methods were the only ones utilized. See Appendix A for others. 
all three participants. One practitioner noted the response to magnetic unruffling as "patient responded well" and communicated about heat over certain chakras. Another described the participant's field as being depleted and feeling "congestion over the right breast-lower abdomen." The third practitioner noted heat in the field over the breast area and "a vacancy felt in the aura at the sacral level."

Observational and dialogical generation of data. The researcher observed the Healing Touch session between the practitioner and the participant. When observing the session, thoughts, feelings, ideas, images and perceptions of the researcher were documented, and thus, bracketed to allow the fullness of the Healing Touch encounter to evolve. Bracketing assisted with facilitating a "purer" description of the experience. All verbal and nonverbal interactions between the practitioner and cancer patient were documented. After the encounter, the Healing Touch practitioner was asked to fill out a form as to which methods were used and if they were used as had been taught or if they were modified. An area was available for the practitioner to comment of the encounter (see Appendix D).

The interviews with the cancer patients were done immediately after the session to permit freedom of expression of her unique experiences. All interviews were audiotaped. Open-ended questions were asked, beginning 
with 'What is the meaning of receiving Healing Touch to you?' Other questions were asked based on responses to questions to fully evolve a description and meaning of the experience. The engaging of the researcher and the participant is a "cue-taking, talk-turning, researcherbracketed, dialogical-dialectical interactive process..." (Ray, 1991, p. 185). The interview ended when the participant had fully expressed the description of the encounter. Each interview time lasted 35-40 minutes. All audiotaped interviews were transcribed to text by the researcher.

Data Analysis

The Process of Phenomenological-Hermeneutical Reflecting and Transforming is the third step in Ray's methodology. The flow of analysis occurs through reflection of presence, transcription of data as text, bracketed reflection, attention to the language in text, identification of descriptive experiences, interpretive reflection, transformation of themes to metathemes, phenomenological reduction, and linguistic transformation (Ray, 1991).

Reflecting on the presence of the participants' beings is necessary in order for the researcher to be authentically present with the data as it emerges. In doing so, the researcher is able to Be-in-the-world (intersubjective) and Be-of-the-world (see into the world or experience) of the 
participant. The verbal and nonverbal data obtained by the Healing Touch encounter was transcribed to text by the researcher. This allowed for the researcher to dwell with the data and become one-with the essence as it gives itself to be (Ray, 1991). Bracketed reflection during the first encounter with the data permitted the researcher to see the experience as it was meant without imposing any presuppositions or prehistory to the phenomenon.

After the text was completed, the researcher highlighted the descriptive experiences to illuminate the participant's language of the experience. Interpretive (unbracketed) reflecting was then done to reveal the emerging themes. In doing so, "the history or horizon of meaning of the researcher is brought into being in the dialectic of consciousness and the text" (Ray, 1991, p. 186). Transformation of emerging themes in text was done by cocreating linguistic abstractions and metathemes.

Phenomenological reduction, or intuiting, is the researcher's returning to the nature of the phenomenon and "grasping the unity of meaning as a direct, unmediated apprehension of the whole of the experience" (Ray, 1991, p. 186). This leap of insight is the intuitive knowing of the essence of the phenomenon. As the meaning was grasped, linguistic transformation of data to themes or metathemes completed the analysis (Ray, 1991). 
Theory of Meaning

Movement to a Theory of Meaning is the fourth step in Ray's methodology. By "putting together" a theory of meaning, the researcher helps provide a phenomenological meaning of caring. The generation of a theory, in this study, provided an integral understanding of the esthetic act of Healing Touch. As such, it provided a universal meaning to the experience (Ray, 1991).

Dialoguing with Written Texts

The fifth step is Dialoguing with Written Texts: Examining Similarities and Differences. It was within this step that the literature review was done. This process involved the comparison of the theory of meaning with existing literature to denote similarities and differences. In doing so, it added value to existing theories and literature as well as provided implications for nursing research, education, administration and practice (Ray, 1991).

Credibility and Significance

The last step of Ray's methodology is the establishing of Credibility and Significance of the Process of the Caring Inquiry. By affirming and confirming with the participants, the researcher was able to bring universal meaning to the Healing Touch experience. The acceptance of reality-as-meant by the experience of the participants provided the researcher with an expanded view of reality and assisted in 
broadening the human perception in relation to other experiences. As such, it helped deepen and expand the possibilities of being (Ray, 1991).

The Caring Inquiry process permitted the researcher to study the experience of the life-world of other. Through a series of nonlinear, interwoven steps, the meaning of the experience of receiving Healing Touch became known. The use of the compassionate "we" enabled the researcher to experience the impact of one on another as well as coparticipate in the encounter in a caring way. The analysis and results of the data provided the researcher with a unique and meaningful perspective on Healing Touch. 


\author{
Chapter 3 \\ Analysis and Results of the Data \\ Data Analysis
}

The analysis of the data through the Process of Phenomenological-Hermeneutical Reflecting and Transforming began with the reflection of presence, transcription of data to text, bracketed reflection, attention to the language in text, identification of descriptive experiences, interpretive (unbracketed) reflection, transformation of themes to metathemes, and phenomenological reduction. By completing this, the researcher was able to identify a unity of meaning.

Reflecting on the presence occurred prior to the transcription of text from audiotaped data, before the bracketed reflection and throughout the interpretive reflection. By meditating for approximately 20 minutes prior to each step as stated, the researcher was able to be fully aware and open to the process and the information which was forthcoming. It allowed the researcher to "Be-of-the-World" and "Be-in-the-World" appropriately.

During the transcription phase, the researcher held in abeyance any preconceived notions of Healing Touch and dwelled with the data as it gave itself to be. By repeated review of the audiotaped data during transcription to ensure accuracy, the researcher was able to hear and feel the essences (meaning) which were presenting themselves. By 
transcribing the data, the researcher was able to relive the experience and return to the moment.

Bracketed reflection was done for each of the first two readings of the transcribed text. The first reading was done very slowly with the researcher highlighting descriptive words and phases, capturing the meaning of the experience as Iived by the participant. The second reading was to insure accuracy of those descriptions and to insure no others were missed. By remaining pure to the bracketing, the descriptions of the experience were easily revealed.

Interpretive (unbracketed) reflection was done by first reading notes taken during each Healing Touch session. By reading these notes before reviewing the transcribed texts a third time, the researcher was able to fully relive the experience as a coparticipant. The thoughts, feelings, and observances noted during each session permitted the themes and metathemes to reveal themselves to their fullest extent. Some examples of notations include, "I feel pulled to help the healing process," the "room is very quiet and relaxing," and the "healer looks gently into the face of client."

While interpretive reflecting during the reading of the first session's text, the whole of the experience revealed itself instantly. All the themes and metathemes emerged completely. The relationship between the Healing Touch practitioner and the participant was also made evident. In addition, the Theory of Meaning emerged. The researcher read 
the other two texts using the same process to confirm the meaning elicited. As caring person, the researcher became emotional because the experience was a shared one between the participants, the healers and the researcher. The compassionate "we" became known.

\section{Results of the Data}

The compassionate "we" became evident during the sessions themselves as well as when the researcher analyzed the data. As the researcher observed and analyzed the sessions, distinct interactions were noted between the cancer patient participants (CPP), the Healing Touch practitioners (HTP), and the researcher. The interactions assisted the participants to experience oneness/wholeness and was made obvious in the unfolding of the themes. The expressed themes enabled the CPPS to become aware of the body-emotion-mind-spirit of the self. From the themes, more abstract metathemes were elicited. By a change in consciousness the whole of the encounter, or unity of meaning, was made known and expressed (see Figure 1). Interactions

During the sessions, the HTP and the CPP showed a distinct pattern of interacting with each other: caring, connecting, opening, cocreating, and being-one-with. This was not seen as necessarily linear, however, for purposes of clarity it will be discussed as such.

Caring. Caring was evident by the dialogue and actions 


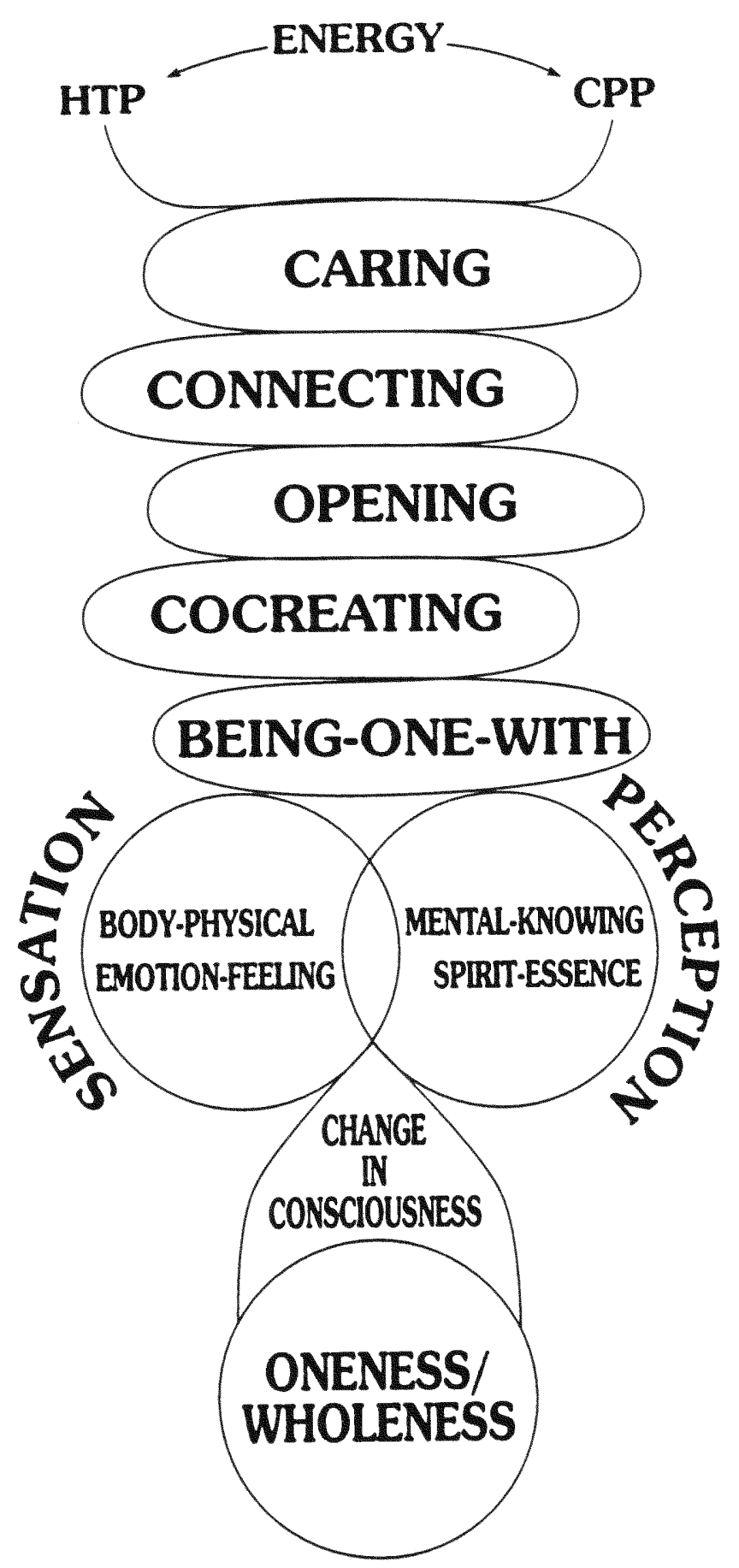

FIGURE 1. Rhythm of Oneness through Energy. HTP represents Healing Touch Practitioner. CPP represents Cancer Patient Participant. 
of each to the other. By the HTP assisting the participant onto the table, inquiring about comfort, explaining the hand movements, and the facial expressions made during the session, they all manifested the pattern of caring. For example, one participant was asked if she wanted a blanket on top of her for warmth. Moreover, pillows were adjusted to comfort and soft soothing words were used in the explanation of Healing Touch. Another example was the look of one HTP serenely gazing into the face of the participant intermittently throughout the session. The participant showed caring by offering water to drink, inquiring about the room space and temperature, and hugging the HTP after the session was completed.

Caring was also revealed in the interviews after the sessions. Terms such as trust, cared for, loving, and helping were noted in terms of how the CPP felt in regard to the relationship with the HTP. For example, one CPP stated, "It made me feel happy and warm and cared for." Another CPP stated,"...I felt very comfortable with her and I was able to relax."

The researcher also felt caring for both the HTP and CPP during the encounter. It was difficult to stay separate from the interaction. One "bracketed" notation was "feel overwhelming love, become teary at site." The aesthetics of each session created a pull to be a coparticipant and assist with the therapy. 
Connecting. The connecting experience which occurred manifested as the CPP connecting with self and with the HTP. As each CPP connected to self, distinct physical, emotional, mental or spiritual occurrences revealed themselves. Each described how the therapy felt physically, such as heat, shock, or magnetic pull. The sensations connected each CPP to the treatment and the awareness to their bodies increased or decreased.

The emotional connecting was experienced as feelings of caring, comfort, safety and being embraced. One CPP stated how the touch made her "feel happy and warm and cared for." Mental connecting occurred when sensations were felt in areas where the CPP's had a particular problem or the treatment had triggered a memory. For example, one CPP was experiencing abdominal discomfort unrelated to the treatment and stated, "...I myself know what's going on, so I was able to connect." To another CPP, her stated feeling about an electric current during the session was a confirmation that "something was happening."

Spiritual connecting was evident in all three CPPS. One had connected to her guardian angel. Another had memories of someone who had prayed for her when she was first diagnosed. The third spoke about "a sense of spirituality with light." The connecting experience of the CPPs to the HTPS was also evident during the interview. Each spoke of the comfort and trust they felt towards the HTP in order for them to 
receive the treatment. One CPP described how she felt she could "let her do whatever she felt was necessary." She stated how she "could feel exactly where she was, ...even when she wasn't touching me." The sense of trust allowed for the connection to occur and the full of the experience to evolve.

Opening. The opening experience which occurred within each person permitted the encounter to proceed. Opening for the HTP came through the process of centering. The HTP, prior to the session, prepared herself to be open and receptive to the energy and intuitive knowing which occurs during a Healing Touch session. It is by this process that the full extent of the healing is possible. It was described by one HTP as if the CPP "welcomed to [sic] energy that was coming in."

The CPRs each related opening as feeling safe and being relaxed. As such, the $C P P$ was open to receive and experience the treatment. One participant described this as "sort of a letting go..., whatever happens is going to happen..., It wasn't until I got myself calmed down enough that I became open to what she was doing..." Another stated, "it was the most free, lack of control needs, safe, secure feeling I'd ever been in."

The researcher felt the relaxing and calming sensation during each session. It was aesthetically peaceful and relaxing to observe and to actually feel the effects of the 
treatment on another in the process. Even the cat at one home fell asleep next to the CPP during the session and stirred only after the session was completed.

Cocreating. The cocreating experience between the HTP and CPP was evident in all sessions. The HTP, by doing techniques determined through the assessment of the energy fields and chakras, as well as the conversation during the sessions between the HTP and CPP, provided the opportunity for the cocreation of the experience. The HTP was able to notify the CPP of sensations or feelings detected in specific areas and dialogue with the CPP to determine any significance of the sensation or feelings identified. In this way, the HTP was cocreating the experience through the energy system and fields of and around the body of the CPP.

The CPP in turn, participated in the cocreating of the experience by reflecting back to the HTP verbally or nonverbally. One CPP described it as if the HTP was "actually putting their good health into you..." still another described the experience as "you're not alone in the experience, it's a shared experience."

During interpretive reflecting and the reading of the notes taken during each session, the researcher had documented in her "bracketed" notes the concept of cocreating care while observing a session. The continued drawing of the researcher into the experience as each session took place revealed how the observer is just as much 
a participant in cocreating an experience as those actually involved in the process.

Being-one-with. The being-one-with that was experienced was described as the HTP and CPP being "a mesh," having a "sense of bonding," and the sensation that "we were just one." It is through this component of the interaction that the HTP is able to live the experience of other through energy. In addition, the CPP is able to experience a sense of blending or of being "symbiotic" to the HTP whereby, as one CPP aptly stated, "there was no sense of the person..., just this unique bonding with two souls, two bodies..." Only through the interactions between the HTP and CPP in caring, connecting, opening, cocreating, and being-onewith in a nonlinear, interconnecting, and overlapping process, was the experience of receiving Healing Touch fully capable of emerging and its meaning elicited. Through the expressed themes of body-physical, emotion-feeling, mentalknowing, and spirit-essence, the researcher was able to determine the metathemes of sensation and perception. The themes were seen as individual entities but often had overlapping qualities with each of the others. The sensation and perception of oneness/wholeness which occurred emerged through a change in consciousness during the session. From this, the unity of meaning, or Rhythm of Oneness Through Energy, became known. 
The metatheme of sensation was identified through the analysis whereby the themes of body-physical and emotionfeeling were the main components (see Table 2). It is through sensation that one is able to sense or feel both physically and emotionally the energy and its effects that is present during the Healing Touch session.

Body-Physical. After each session, the CPPs indicated the body-physical component of having received the treatment. Although each had distinct sensations, the terms used by the CPPs signify a related experience. For example, the terms for temperature and movement were identified. These included heat, hot, cold, current, shock, magnetic pull, burst of energy, and air bubbles. Other terms were a feeling of being surrounded, embraced or a sense of weightlessness. The descriptions for the body-physical ranged from the concrete to the abstract. Yet, the one thing all participants stated was the deep relaxation they experienced that none had felt with any other relaxation modality utilized previously.

Emotion-Feeling. The emotion-feeling theme was denoted in the multitude of descriptions concerning the emotion of the treatment as well as the feelings that accompanied it. The varied responses revealed the layers of emotion and feelings which are present in each encounter between two 
Table 2

Sensation

Theme

Narrative

Body-Physical

"I felt that her hands were holding me whether she touched me or not."

"It was just a magnetic pull I could feel. So, maybe something was pulling out of me."

"It was, uh, it was like a burst of energy."

Emotion-Feeling

"I was just very happy to be held and touched, and it felt wonderful and loving."

"It wasn't until I got myself calmed down enough that I became open to what she was doing...."

"... I was having these feelings that, I hope, that this is helping that spot."

Note. Examples of narrative from interviews post Healing Touch session. 
people. In turn, it supported the caring mode of being as descriptions of the theme became known. For example, descriptors such as wanted, wonderful, calm, loving, happy and peaceful revealed the varying dimensions of each individual experience. One key emotion-feeling that was stated by all CPPs was the feeling of being safe and protected, a sense of trust.

Perception

The metatheme of perception was determined by the themes mental-knowing and spirit-essence (see Table 3). It is through perception that one is able to experience knowing and spiriting. These two themes revealed terms that are more abstract than those found in sensations, yet distinctly identify each accordingly.

Mental-knowing. The mental-knowing that was elicited from each $\mathrm{CPP}$ revealed that of present knowing, past knowing, and future knowing. In addition, it identified an "other" knowing, that is knowing another on a different level of consciousness. The present knowing consisted of the thinking about the session as it was occurring. Past knowing revealed itself in the memories induced while receiving Healing Touch. Future knowing was made evident in the CPPS acknowledging the need to learn more about themselves and the healing processes available to them. The other knowing was the most interesting since it revealed the participants knowing the whereabouts of the Healing Touch work when their 
Table 3

Perception

Theme

Narrative

Mental-Knowing

"And at times, I had

reminisces of my mother's

touch."

"And then I thought, I have to stop thinking about this. I have to let it just happen, whatever it's going to be."

"I mean, because I myself know what's going on, so I was able to connect."

Spirit-Essence

"I felt as if I were, my entire being, my spiritual being, my inner being, my body, the meaning of it to me was I was joined in all three areas during the experience."

"And so, I, I [sic] feel like I'm being given by God the things I need to heal me."

"I believe that I do have an angel, that's watching over me. And so, by bringing me into situations like this, ... that my angel is taking me into new, new [sic] circles to help me towards this end."

Note. Examples of narrative from interviews post Healing Touch session. 
eyes were closed. The CPPs were able to identify the location of the HTP while in a state of deep relaxation. Spirit-Essence. This theme was consistent with all CPPs. Each defined this theme according to their own belief system. Yet, each one had an underlying connection with the others. It encompassed the self as inner being, a belief or faith in something greater than themselves, and a being of Higher Power. The theme of spirit-essence appeared to provide comfort for the CPPS and gave each a sense of strength and courage to endure their present state of health or dis-ease.

Change in Consciousness

The sense of oneness/wholeness occurred through a change of consciousness. It was through this alteration in state of being that the CPPs were able to know themselves as whole. One CPP described herself as falling asleep but "was completely aware of everything that she was doing." Another described it as floating, leaving the table, and going "from the physical to this holistic feeling, this whole, this total feeling of every part of me was involved in the process." She discussed being transported into the sky to mesh with colors not as a physical being but as part of the colors.

Wholeness was described differently by each of the CPPS. Each was able to define wholeness within their framework at the time of the Healing Touch session. One 
described it as "I felt that my body, my body [sic], my mind, and my spirit was drawn together, unified, during the experience." Another referred to it as her desire for healing and wellbeing through balance. Still, another described it as having wellness and being able to participate in life.

Change in consciousness also included the CPPS' awareness of person without boundaries, both themselves and the HTPS. It permitted them to share self with other on a different level. By the change in consciousness, the CPPs were able to experience the oneness/wholeness of each to the other and of the other. As such, one is not separate from the other in higher levels of consciousness, we are but one. Rhythm of Oneness Through Energy

The unity of meaning that revealed itself in the experience of receiving Healing Touch is the Rhythm of Oneness Through Energy. It is the connecting, opening, and cocreating through caring, the wholeness of each to become one through rhythms of energy. Energy, as the fundamental component, permits the whole of the experience to emerge. By the use of the energy within and around us, one is able to experience the oneness/wholeness. One CPP discussed the flow of the energy and its effect on how every part of her was involved in the process of healing. When describing massage she had received previously versus Healing Touch, she stated "I could not get into this same kind of rhythm that I felt 
here."

The rhythm of energy relates to the physical sensation of the treatment, the movement through the physical, emotional and mental experiences to the spiritual component, and the connection between the HTP and the participant. The descriptive terms used by the CPPs of energy, such as movement, vibration, current, and force, revealed the experience as a dynamic, evolving and life changing process. This multidimensional, integrative, nonlinear process occurs in each, the HTP and CPP, individually and together. It is through this rhythm that the sensation and perception of oneness/wholeness through a change in consciousness can occur.

The analysis of the data using the Caring Inquiry process, permitted the researcher to coparticipate in the Healing Touch session and allow the compassionate "we" to assist in identifying the unity of meaning. The results of the data reveal the experience of receiving Healing Touch as a nonlinear, interconnected process whereby, with the use of energy within and around the body, the oneness/wholeness of self is elicited through a change in consciousness. The Rhythm of Oneness Through Energy describes the meaning of the experience with energy, being the dynamic, fundamental component, assisting this process. In order to support the findings, a thorough literature review was undertaken within the disciplines of nursing and philosophy. 


\section{Chapter 4}

Literature Review

In order to support the findings, the researcher looked to nursing literature, nursing theory, and philosophy. By dialoguing with written text, similarities and differences in the theory of meaning was noted. As such, it will provide support for the experience of receiving Healing Touch, the use of Healing Touch as a treatment modality to health, and add support to current nursing theories. Nursing Literature

Although no literature was found in regard to Healing Touch, several works were located regarding a similar therapy, Therapeutic Touch. These studies include the use of qualitative methods (Barrington, 1994; Heidt, 1990; Lionberger, 1986; \& Samarel, 1992) and quantitative methods (Keller \& Bzdek, 1986; Meehan, 1993; \& Quinn, 1984, 1989) in assessing Therapeutic Touch. The range of study areas were diverse. They included but were not limited to tension headache (Keller \& Bzdek, 1986), postoperative pain (Barrington, 1994; Meehan, 1993), and the lived experience of receiving Therapeutic Touch (Heidt, 1990; Samarel, 1992).

The key findings in these studies that relate to the present research are the sense of relaxation (Barrington, 1994; Heidt, 1990), the multidimensionality of the person (Samarel, 1992), and the feeling of being cared for (Lionberger, 1986). The sense of relaxation felt by the 
participants of this study is congruent with the relaxation found in those studies mentioned. By relaxing, the participant is allowing the full effect of the treatment to occur.

The experience of multidimensionality of the person as body-emotion-mind-spirit in this study related to Samarel's (1992) work. She used a phenomenological method to determine the lived experience of receiving Therapeutic Touch. Her sample size of 20 participants had received Therapeutic Touch ranging from 2 days to 7 years. The concept of wholeness in the present study was evident as in Samarel's research despite the fact that Samarel did not identify it as such. Samarel also found the experience of receiving Therapeutic Touch as a linear process in those persons receiving the treatment more than one time. The findings of this study were not the same with subjects receiving the session only once. Although this study's findings are written in a linear format, the descriptions of the participants' experiences revealed the nonlinear aspect of the self and the experience. If further sessions of Healing Touch were offered, it is possible that the area of linear versus nonlinear processes could be better argued.

Lionberger's (1986) phenomenological study of Therapeutic Touch revealed the caring aspect of giving that treatment modality from the perspective of both the nurse and the recipient. In congruence with Lionberger's work, the 
study presented here also revealed the caring mode during the post Healing Touch treatment. Each participant stated they felt cared for by the HTP during the session. In addition, each felt the caring for self to reflect on their current health status and their desire for wellness and wholeness.

Another interesting component detected in this present study is the "opening" which Heidt (1990) described. Heidt found opening to the universal life energy to be the primary experience of Therapeutic Touch, whereas this researcher found opening to be only part of the relationship encounter. The CPPS in this study described the opening as being calm and relaxed in order to receive the treatment (the energy). Another point of interest is Barrington's (1994) phenomenological study of the lived experience of Therapeutic Touch during post-operative pain phenomena. Her findings revealed patterns manifested as experience, perception, and expression. Her informants stated experiences which relate closely to the metatheme sensation in this study and her examples fall in line with the physical and emotional components identified as themes in this research. Perception as the knowing component was the shared entity identified in both studies. This research also included the theme of spirit as perception which Barrington's informants did not identify. In addition, she noted expressions as a third component which this researcher 
found to be part of the overall process of identifying sensations and perceptions, not as something distinct from the two.

Current literature is only reflective of the beginning understanding of what occurs in energy therapy, whether it be Therapeutic Touch or Healing Touch. Since both modalities use energy as the core, it will be interesting to see what future studies reveal and how they will compare to present research.

Nursing Theory

In regard to the findings of this study, it became clear that several nursing theories are supported. Although no one theory is explicitly supported, each is represented in some way. Rogers' (1986) Science of Unitary Human Beings, Newman's (1994) Health as Expanding Consciousness, Parse's (1995) Human Becoming theory, and Watson's (1988) Transpersonal Caring theory are nursing theories whose components can be distinctly identified in this study.

Rogers' (1986) Science of Unitary Human Beings is probably the most supported. According to Rogers, unitary human beings are irreducible wholes and identified as energy fields as the basic element. These fields are open and continuous with the environment and are integral with each other. Multidimensionality is the nonlinear domain lacking spatial and temporal entities and characterizes the human and environmental fields. With concepts of energy fields, 
irreducible wholes, openness, and multidimensionality, the use of Healing Touch as a treatment modality is supported. Healing Touch is based on the premise that persons are energy with energy fields. It is also understood that persons are more than the sum of their parts, in other words, they are irreducible wholes. Due to the body-emotionmind-spirit concept, persons are also thought of as multidimensional with the self and the environment, and the effect of Healing Touch can affect some or all of the whole. This is attained through the openness of the fields and the relationship between the HTP and the recipient.

Newman's (1994) Health as Expanding Consciousness is also supported in this research. Newman holds pattern lof energy) of the whole as health as her basic tenet and that health is expanding consciousness. She sees the person as whole with a specific pattern of energy. It is this pattern in which health becomes known. Persons are defined by their patterns of consciousness whereby consciousness is the informational capacity for the person to interact with the environment on multiple levels. It is through evolving or expanding consciousness that health is made known.

As seen in this study, Healing Touch allowed the participants to view oneness, or wholeness, through selfdefined meanings of wellness, wellbeing, and health. By a change in consciousness during the session, the participants were able to view this meaning of health for themselves. The 
HTP facilitated the process by repatterning the individual's energy field to allow the meaning of oneness/wholeness to come forth.

Like Rogers' theory, Earse's (1995) Human Becoming theory adheres to the description of humans as whole and recognized through patterns. These patterns are in mutual process with the universe. Humans and universe cocreate rhythmically. This human-universe interrelationship assists in defining health. Health is the process of becoming as described or experienced by the person.

In supporting Parse's theory, the Healing Touch research supports the notion of humans as whole interrelating rhythmically (through energy) with others and their environment to cocreate meaning of health. Through Healing Touch, the HTP and CPP cocreate the meaning of the experience of receiving Healing Touch through rhythms of their patterns. As such, the CPP was able to define health as meaningful to herself and identify the process needed to transcend to it.

Watson's (1988) theory of Transpersonal Caring is based on human-to-human caring whereby through intersubjectivity one helps the other find meaning and assist in self-healing. The person is viewed as possessing three spheres of being-mind, body, and soul--which are influenced by the concept of self. When there is harmony with the mind, body, and soul, person and self are one. This person experiences and 
perceives moment to moment through her/his own frame of reference to create meaning.

Through intersubjectivity, the HTP and the CPP were able to create a caring moment by the use of Healing Touch whereby the CPP was able to view self as healthy person, whole, through her own frame of reference. In doing so, the meaning of the experience and the process of self-healing were made known.

Philosophy

Eastern philosophy has greatly impacted the notion of healing and health. According to Pachuta (1989) all healing systems originated in religion and philosophy. Origins of ancient Chinese medicine lie in three philosophical notions which permeate most systems of Eastern healing: Tao, Ch'i, and Yin/Yang. Tao is the Way--the way the universe unfolds, oneness, cosmic and eternal. Ch'i, the fundamental component of Chinese medicine, is the universal energy, the vital life force, and the flow. It is the energy, internal and external to us, and the balance and harmony of this energy which means health (Pachuta, 1989). Yin/Yang are the fundamental dualities of the universe, yet form a unity of the circle. This circle represents the whole universe of which they are separate yet the same (Pachuta, 1989). While these ideas remain constant today in Eastern cultures, Western systems have chosen to ignore their roots and deny the importance of nature and spiritual connectedness. 
In ancient times, Eastern and Western systems and philosophy were similar in thought. That is, the teachings of Ch'i Po and Hippocrates respectively founded the traditions for Oriental and Western medicine (Pachuta, 1989). Both agreed on the philosophy of healing, had similar descriptions of disease, and perception of disease. They agreed to the existence of internal and external factors causing disease. They both felt that the internal factor, spirit, had an incredible impact on both the patient and the practitioner. It wasn't until Descartes' push for the mindbody split that Western medicine abandoned its original premises (Nasr, 1996). Eastern medicine, however, has remained almost unchanged.

In Eastern thinking, one continually seeks harmony and balance through the oneness of the universe (Pachuta, 1989). Sameness coexists with the uniqueness of the individual. People are treated within the body-mind-spirit context, which includes emotion as part of the mind. All things are interconnected and therefore play a role in the healing of a person. The person is responsible for his/her own healing with the practitioner facilitating the process in becoming well. In Eastern medicine, energy as the basic component of life is treated. Crucial to healing is the centeredness and wholeness of the practitioner.

In contrast, western medicine focused on treating the parts of the person without honoring the body-mind-spirit 
component. The treatment of disease, which is viewed as external to the person, is based on the symptoms rather than the whole person. Little or no attention is given to the internal factors of disease and spirit is generally completely ignored. It removes a person's responsibility for health and healing and places the practitioner in a position of authority (Pachuta, 1989).

Fortunately, there is a renewed interest in the bodymind-spirit component of health. Western medicine is in the beginning stage of recognizing the impact of incorporating the whole of the person in the healing process and giving responsibility back to the individual person. Research is being done in universities and institutions across the country. Caution must prevail in the use of purely reductionist techniques for determining the wholeness of an individual. A person is more than the sum of the parts and if the parts are looked at separately, they will not provide an accurate picture of the underlying problem. One needs to look at the whole person in order to treat appropriately.

By looking to nursing literature, nursing theory, and philosophy, the researcher was able to provide support to this study. Nursing literature provided a rich base of research already done using a similar therapy, Therapeutic Touch. Nursing theories were supported by the Healing Touch session and the outcome of this research. The use of Healing Touch as a treatment modality was enhanced by philosophy. 
The implications for nursing are enormous and future studies are greatly needed to assess its true value as a healing modality . 


\section{Chapter 5 \\ Discussion}

The impact cancer has on the individual and the family are immense and nursing has the responsibility to care for them the best they know how. Therefore, the implications for nursing are numerous. By using Healing Touch on cancer patients, this study revealed the need to further identify which techniques are best for each disease process and complications, coping needs, spiritual issues, and mental integration of the events in their life. In addition, Healing Touch brings the nurse back to the caring mode and assists with the holistic view of the patient. Implications for Nursing

Healing Touch and its lived experience with cancer patients has numerous implications for all aspects of nursing. It will affect each level of nursing--practice, education, research, and nursing administration. But perhaps, the most significant contribution will be to the discipline of holistic nursing. The results of this study lay an important foundation for nursing as an art and a science.

Nursing practice. Nursing practice will be affected by Healing Touch and the lived experience with cancer patients in that it will force nursing to look into the way it practices. Currently, nursing practice is more focused on task rather than as a discipline of being, knowing and 
doing, in other words, holistic. It has moved from being with the patient during the nurse-patient encounter to one of managing others in the care of patients. Nursing will need to define its discipline and practice and advocate on behalf of patients in order for them to receive holistic nursing care. It will require nursing to work from a comprehensive nursing theory base instead of a medical model base.

Nursing education. Nursing education will be affected by this study by reinforcing the need for educators to teach students about energy therapies. With the nursing diagnosis of energy field disturbance, nurses will need to know what energy fields are, how to assess them, methods of interacting with the fields, and evaluating outcomes of those interactions. Healing Touch provides an opportunity for educators to provide a thorough program for the understanding and implementation of energy healing. Nursing research. Nursing research is already being affected by energy modalities of healing. The need to understand the human energy field and its relationship to health and healing is imperative. New methods of research may need to be developed since all of the effects of energy work are not solely manifested in the physical realm. New measurement tools will need developing in order to quantitatively determine the effects of energy therapy. Qualitative studies need to continue in order to fully 
capture the experience and meaning of Healing Touch and other energy based modalities.

Nursing administration. Nursing administration will be greatly affected by energy therapies since it will force administrators to place a cost value on holistic nursing care and possibly change the way nursing is financed. In addition, policies and procedures will need developing to insure minimum standards for energy therapy. Safety will be an issue to address how qualified practitioners of energy modalities are ascertained. Finally, by recognizing nursing's impact on patient care, nursing administrators can assist in changing the health care environment by placing emphasis on healing the person as a whole, not just by the parts.

Holistic nursing. The discipline of holistic nursing will be advanced. This study provides a philosophical and research foundation for Healing Touch. A theory of meaning has been identified which can be used as a basis for other research. As with any practice, a strong philosophical and research base is paramount for credibility and advancement of the practice.

The lived experience of Healing Touch with cancer patients has shown to have valuable implications for nursing. All areas of nursing will benefit from this study in addition to the patients on which it is used. Only by supporting this modality in nursing will Healing Touch 
reveal its worth in caring for the whole of the patient. Conclusion

The study of the lived experience of Healing Touch with cancer patients, by utilizing Ray's Caring Inquiry, a phenomenologic-hermeneutic method, has revealed a theory of meaning to the experience. The use of Caring Inquiry as method permitted the true meaning of the experience to evolve. The Rhythm of Oneness Through Energy provides a sound base for practice, theory, and future research. Supported by and relating to several nursing theories, the essence of Healing Touch revealed itself as a significant modality in the enhancement of healing.

Through the identification of the themes body-physical, emotion-feeling, mental-knowing, and spirit-essence, the researcher was able to further identify the metathemes of sensation and perception through the practice of interpretation. It is through a change in consciousness that sensation and perception provide the oneness/wholeness of the experience. This oneness is obtained by the rhythms of energy of the HTP and the CPP.

Strengths. The strengths of the findings were revealed to and within the researcher as described in Ray's method. In doing so, the true meaning of the experience was permitted to come forth. By affirming and confirming the results of the study with the participants, they brought credence and significance to the experience. No changes or 
additional interviews were required after this process. All participants were in agreement as to the outcomes. By doing the session in the participants' home, it truly provided a naturalistic environment which led to ease of relaxation during the session.

Limitations. There were several weaknesses which may have affected the outcome. By the cancer patients having been exposed to other complementary therapies, they may have been more aware of the body-emotion-mind-spirit concept. Secondly, by having all female participants, gender differences in the experience could not be identified. Thirdly, the religions of the CPPs were similar, but the religions of the HTPs were different. If all religions had been the same or all different, it may have affected the results. This is especially true if any of the participants were agnostics. Fourthly, the elimination of the first identified HTP, who was replaced by another, may have altered the outcome in an unknown way. Lastly, cultural differences were not identified which may greatly impact the experience.

Further research using both qualitative and quantitative methods is required to continue the search for deeper knowledge in order to assist certain disease symptomatology by holistic measures, to enhance the practice of Healing Touch, and to advance the science of nursing. Future research should be done using cancer patients without 
any experience with complementary therapies. In addition, focusing on males only may provide a different perspective on the lived experience of receiving Healing Touch. Other patient populations need to be studied to determine if the theory of meaning is consistent across all patient populations and cultural groups.

Science is only beginning to touch the surface of utilizing energy therapies as a means to treat clients. Humans, having energy as its core component, are open to new methods of treatment for the acquisition of health and for healing. The focus on wellness and health promotion are paramount for nursing and other health care professionals to address. Only by promoting health through a change in consciousness can nursing fully live up to its responsibilities. 
Barrington, R. (1994). A naturalistic inquiry of postoperative pain after therapeutic touch. In D. Gaut \& A. Boykin (Eds.), Caring as healing: Renewal through hope (pp. 199-213). New York: National League for Nursing.

Beck, S.L. (1991). The therapeutic use of music for cancerrelated pain. Oncology Nursing Forum, 18, 1327-1337.

Bleicher, J. (1980). Contemporary hermeneutics: Hermeneutics as method, philosophy, and critique. London: Routledge \& Kegan Paul.

Boykin, A. \& Schoenhofer, S. (1993). Nursing as caring: A model for transforming practice. New York: National League for Nursing Press.

Brennan, B.A. (1987). Hands of light: A guide to healing through the human energy field. Toronto: Bantam Books.

Bronstein, M. (1996). Healing hands. The Canadian Nurse, 92, $32-36$.

Bruyere, R.L. (1994). Wheels of light. New York: Fireside.

Cohen, J.A. (1991). Two portraits of caring: A comparison of the artists, Leininger and Watson. Journal of Advanced Nursing, 16, 899-909.

Dossey, L. (1995). A journal and a journey. Alternative Therapies, 1, 6-9.

Ernst, E. (1993, July 17). From magic to medicine. New Scientist, 139, 44-45.

Ferrell, B.R., Dow, K.H., Leigh, S., Ly, J., \& Gulasekaram, P. (1995). Quality of life in long-term cancer survivors. Oncology Nursing Forum, 22, 915-922.

Ferrell-Torry, A.T., \& Glick, O.J. (1993). The use of therapeutic massage as a nursing intervention to modify anxiety and the perception of cancer pain. Cancer Nursing, 16, 93-101.

Gerber, R. (1996). Vibrational medicine: New choices for healing ourselves. Santa Fe, New Mexico: Bear \& Company.

Guyton, A.C. (1987). Human physiology and mechanism of disease. (4th ed.). Philadelphia: W.B. Saunders, Company. 
Heidt, P.R. (1990). Openness: A qualitative analysis of nurses' and patients' experiences of therapeutic touch. Image: Journal of Nursing Scholarship, 22, 180-186.

Hover-Kramer, D. (1996a). Assessing and identifying patterns in the energy field. In L. Keegan (Ed.), Healing touch: A resource for health care professionals (pp. 77-89). Albany, NY: Delmar Publishers.

Hover-Kramer, D. (1996b). The chakras and their function. In L. Keegan (Ed.), Healing touch: A resource for health care professionals (pp. 59-76). Albany, NY: Delmar publishers.

Hover-Kramer, D. (1996c). Conclusion with opening to new questions. In L. Keegan (Ed.), Healing touch: A resource for health care professionals (pp. 227-230). Albany, NY: Delmar Publishers.

Hover-Kramer, D. (1996d). Field theory and implications for human caring. In L. Keegan (Ed.), Healing touch: A resource for health care professionals (pp. 45-57). Albany, NY: Delmar Publishers.

Hover-Kramer, D. (1996e). Preface. In L. Keegan (Ed.), Healing touch: A resource for health care professionals (pp. $x v-x i x)$. Albany, NY: Delmar Publishers.

Husserl, E. (1962). Ideas. New York: Collier Books.

Johnston, K., \& Rohaly-Davis, J. (1996). An introduction to music therapy: Helping the oncology patient in the ICU. Critical Care Nursing Quarterly, 18, 54-60.

Joy, W.B. (1979). Joy's way: A map for the transformational journey. Los Angeles: Jeremy P. Tarcher, Inc.

Keller E., \& Bzdek, V.M. (1986). Effects of therapeutic touch on tension headache pain. Nursing Research, 35, 101-106.

Kockelmans, J.J. (1967). Phenomenology: The philosophy of Edmund Husser1. Garden City, NY: Doubleday \& Company, Inc.

Kockelmans, J.J. (1990). Heidegger's "being and time": The analytic of Dasein as fundamental ontology. Washington, D.C: Center for Advanced Research in Phenomenology \& University Press of America.

Krieger, D. (1979). The therapeutic touch: How to use your hands to help or to heal. New York: Prentice Hall Press. 
Leininger, M. (Ed.). (1984). Care: The essence of nursing and health. Detroit, MI: Wayne State University Press.

Lionberger, H.J. (1986). Therapeutic touch: A healing modality or a caring strategy? In P.L. Chinn (Ed.), Nursing research methodology: Issues and implementation (pp. 169-180). Rockville, MD: Aspen Publishers.

Meehan, T.C. (1993). Therapeutic touch and postoperative pain: A Rogerian research study. Nursing Science Quarterly, 6, 69-78.

Mentgen, J., \& Bulbrook, M.J. (1994). Healing touch: Level I notebook. Carrboro, NC: North Carolina Center for Healing Touch.

Mentgen, J., \& Bulbrook, M.J. (1995). Healing touch: Level II notebook. Carrboro, NC: North Carolina Center for Healing Touch.

Miller, S.R. (1996, October 18). Getting in touch with healing. South Florida Business Journal, pp. 3A, $11 \mathrm{~A}$.

Montbriand, M.J. (1993). Freedom of choice: An issue concerning alternate therapies chosen by patients with cancer. Oncology Nursing Forum, 20, 1195-1201.

Moss, T. (1979). The body electric. Los Angeles: J.P. Tarcher, Inc.

Nasr, S.H. (1996). Religion and the order of nature. New York: Oxford university Press.

Newman, M.A. (1994). Health as expanding consciousness (2nd ed.). New York: National League for Nursing Press.

Northouse, L.L. (1995). The impact of cancer in women on the family. Cancer Practice, 3, 134-142.

Nightingale, F. (1859). Notes on nursing. London: J.B. Lippincott Company.

Owens, M.K., \& Ehrenreich, D. (1991). Application of nonpharmacologic methods of managing chronic pain. Holistic Nursing Practice, 6, 32-40.

Pachuta, D.M. (1989). Chinese medicine: The law of five elements. In. A.A. Sheikh \& K.S. Sheikh (Eds.), Healing east and west (pp. 64-90). New York: John Wiley \& Sons, Inc. 
Parker, S.L., Tong, T., Bolden, S., \& Wingo, P.A. (1996, Feb.). Cancer statistics, 1996. CA: A Cancer Journal For Clinicians, 46 5-27.

Parse, R.R. (Ed.). (1995). Illuminations: The human becoming theory in practice and research. New York: National League for Nursing Press.

Quinn, J.F. (1984). Therapeutic touch as energy exchange: Testing the theory. Advances in Nursing Science, 6, 4249.

Quinn, J.F. (1989). Therapeutic touch as energy exchange: Replication and extension. Nursing Science Quarterly, 2, 79-87.

Ray, M.A. (1990). Phenomenological method for nursing research. In N.L. Chaska (Ed.), The nursing profession: Turning points (pp. 173-179). St. Louis: CV Mosby, Co.

Ray, M.A. (1991). Caring Inquiry: The esthetic process in the way of compassion. In D.A. Gaut \& M.M. Leininger (Eds), Caring: The compassionate healer (pp. 181-189). New York: National League for Nursing Press.

Ray, M.A. (1994). The richness of phenomenology:

Philosophic, theoretic, and methodologic concerns. In J.M. Morse (Ed.), Critical issues in qualitative research methods (pp. 117-135). Thousand Oaks: Sage publications.

Roach, M.S. (1992). The human act of caring: A blueprint for the health professions. Ottawa: Canadian Hospital Association Press.

Rogers, M.E. (1986). Science of unitary human beings. In V.M. Malinski (Ed.), Explorations on Martha Rogers' science of unitary human beings (pp. 3-8). Norwalk, CT: Appleton-Century-Crofts.

Samarel, N. (1992). The experience of receiving therapeutic touch. Journal of Advanced Nursing, 17, 651-657.

Scandrett-Hibdon, S. (1996). The history of energy-oriented healing. In L. Keegan (Ed.), Healing Touch: A resource for health care professionals (pp. 11-25). Albany, NY: Delmar Publishers.

Stanwick, M. (1996). Aura photography: Mundane physics or diagnostic tool? Nursing Times, 92, 39-41.

Stapleton, T.J. (1983). Husserl and Heidegger: The question 
of a phenomenological beginning. Albany: State University of New York Press.

Stearns, D.M., \& Whedon, M. (1993). Social well-being and quality of life: Analysis of a journey of cancer survivorship. Quality of Life: A Nursing Challenge, 2, 23-31.

Streubert, H.J., \& Carpenter, D.R. (1995). Phenomenological research approach. Qualitative research in nursing: Advancing the humanistic imperative (pp. 29-49). Philadelphia: J.B. Lippincott Co.

Watson, J. (1988). Nursing: Human science and human care. New York: National League for Nursing.

Zacharias, D.R., Gilg, C.A., \& Foxall, M.J. (1994). Quality of life and coping in patients with gynecologic cancer and their spouses. Oncology Nursing Forum, 21, 169917. 
Appendix A 
Techniques Used in Healing Touch

1. Centering - the process of letting go of the ego self to be fully open to other. In doing so, one connects with the Higher Power or Universal Energy (Hover-Kramer, 1996). 2. Assessing - the use of the hands to feel the energy fields and chakras to detect subtle vibrations as perceived by the healer's kinesthetic, auditory, visual, and intuitive senses (Hover-Kramer, 1996).

3. Unruffling - a technique in Healing Touch and Therapeutic Touch whereby the person doing the therapy (healer) smoothes the energy field of another (healee) by slow sweeping motions of the hand through the energy field (Hover-Kramer, 1996; Krieger, 1979).

4. Modulation of energy - the transfer of energy to another by means of indirect or direct application of hands to an area over or on the site the healer senses energy is needed (Hover-Kramer, 1996; Krieger, 1979).

5. Stopping or Closure - the intuitive knowing when to stop the transfer of energy (Hover-Kramer, 1996; Krieger, 1979). 6. Magnetic Unruffling - a technique used to clear the entire body of congestion in a systematic way. In doing so, it clears the body's energy field. The hands act as rakes as they are moved from head to toe 30 times, or about 15 minutes (Hover-Kramer, 1996; Mentgen \& Bulbrook, 1994). 7. Chakra Connection (Full Body Connection) - a technique used to cleanse or chelate specific points on the body. Each 
point is held for $1-3$ minutes. The process starts at the feet and moves upward connecting each lower extremity joint areas, root through heart chakras, upper extremity joint areas then throat chakra to transpersonal point (about 18 inches above the head) (Hover-Kramer, 1996; Mentgen \& Bulbrook, 1994).

8. Ultrasound - this technique uses the hand with thumb and forefinger held together, directing energy from the palm through the fingers like a beam of light. The hand is moving continuously back and forth in short motions. This is for deep tissue penetration (Hover-Kramer, 1996; Mentgen \& Bulbrook, 1994).

9. Laser - a technique similar to ultrasound, except one or more fingers are pointed to an area needing energy. This powerful method is used for a few seconds to a minute to deliver energy for deep tissue penetration (Hover-Kramer, 1996; Mentgen \& Bulbrook, 1994).

10. Chakra Spread - a very powerful technique used for times of crisis, terminal illness, life transformation, pre- and postsurgery, and for severe pain. This technique heals on a deeper level. The healer holds each foot individually, then each hand individually for one minute before beginning the sequence. The next series of steps are repeated three times each. Starting at the head over the crown chakra, the healer slowly spreads both hands outward. Then over the brow, throat, heart, solar plexus, sacral, root chakras, the 
knees, and the ankles. The healer pulls off the energy from the feet by cupping hands on both sides of the foot and pull off the toes. After three series are completed, the healer holds one hand over the heart chakra and holds one hand of the healee. This technique can be done with the person sitting or lying down (Mentgen \& Bulbrook, 1994).

11. Scudder Technique - is a light touch energy technique to remove stagnated energy that accumulates in certain areas. It is used to promote relaxation and energy flow. This may be done with the person sitting or lying down. Each step is done three times. The practitioner starts by brushing persons brow outward from the face, then brush over and outward from the eyes. Next, the practitioner brushes down from the top of the head, around the ears, and tugs on the ear lobes. The practitioner then starts from the chin and brushes upward behind the ear. Starting on the left side, the practitioner brushes from the shoulder to the elbow, then the elbow to the palm. Massage of the palm and fingers is next, then while grasping each finger individually pulls off excess energy. The practitioner then scoops energy out of the suprasternal notch. Starting from the sternum, the practitioner lightly brushes down the sternum, over to the side he/she is working on. Next, he/she brushes from the hip joint to the back of the knee, then knee to inner arch of the foot. The feet and toes are massaged and each are grasped and tugged lightly to remove excess energy. The same 
is repeated on the other side. The practitioner then goes behind the person and breaks up the energy across the shoulders like little karate chops and brushes the energy off. Finally, the person is asked to sit forward. The practitioner starts lightly brushing upward and outward from the coccyx, up the back, to the neck. The practitioner then brushes this energy off the shoulders (Mentgen \& Bulbrook, 1994).

12. Mind Clearing - the technique used to balance the energy in the head and to induce deep relaxation. This may be used with the person sitting or lying down. Each position is held until the practitioner intuitively feels the area full. The practitioner places his/her fingertips along the throat just above the clavicles, then three fingers vertically along the spine at the base of the skull and three fingers vertically in the middle of the forehead. The fingers of both hands are then placed along the occipital bony ridge and a gentle pull is exerted. From there, the hands are slid up the skull where the two thumbs rest on the middle of the head along the suture line and the fingers of both hands point downward on the head. Next, three fingers of each hand are placed vertically above the ears. Set four fingers of each hand on the forehead vertically from hair line to just inside the brows. Slowly, spread these fingers outward towards the lateral side of the forehead. Fingers are then placed on the mandibular joints and gently massaged. The practitioner 
next brushes around the face gently three times from hairline of the brow, outward around the eyes, down the cheeks to the mandibular joint. The practitioner finishes by gently cupping both cheeks with the palms of his/her hands with the fingers pointing downward (Mentgen \& Bulbrook, 1994).

13. Spiral Meditation - involves opening the energy field to allow for deeper work. It's sequence appears like a spiral beginning with the heart chakra and spinning outward over each chakra in a specific manner. It involves using two hands together to make the motion and hold the space. The sequence is the heart to the solar plexus, to high heart (located between the throat and heart), spleen, sacral, throat, root, brow, knees, crown, feet, transpersonal point (18 inches above head). After the energy field is opened, any other techniques may be used. Once all the healing is complete, the practitioner closes the field by performing the same sequence in reverse (Joy, 1979; Mentgen \& Bulbrook, 1995).

14. Back and neck techniques - these techniques work together on the etheric layer to provide energetic relief to the back and neck. An assessment of the back is done first by penduling the chakras on the back to see if they are open or closed. To pendulum, one uses an object on a string to assess the spin of the chakra. In this case, initially the pendulum is hung over the chakras in the back (throat, 
heart, solar plexus, and sacral). Normally, all areas would spin in a clockwise manner. If blockages are present, the pendulum may swing counterclockwise, vertically, horizontally, elliptically, or become motionless. An assessment with the hands is done similar to TT. The practitioner visually notes any imbalance or positioning of the back, neck and legs. Next, connecting the lower body is done similar to the Chakra Connection up to the hips. To open the spinal energy flow, the practitioner places one hand on the base of the neck and the other at the base of the spine. Energy is sent between the two hands until a balance is felt. Vertebral spiral is done next by using the thumb and forefinger together to draw 10-12 circles up along the sides of the spine. These circles are clockwise on the right side of the spine, and counterclockwise on the left side. At the end of the spirals, the practitioner pulls the hand away from the body to release the energy. To identify specific vertebral blockages, one again pendulums over each vertebrae while grasping each with the thumb and forefinger. If a block persists, then the practitioner will use the Hopi technique. This technique begins by placing three fingers from one hand on one side of the spine and three fingers from the other hand on the other at the site of the blockage. This position is held until vibrations reduce. At this point, place three fingers from both hands on one side of the spine, and the two thumbs on the other side as if 
grasping the spine in two hands. Again, once the vibrations reduce, the person takes three deep breaths and on the third exhalation, the practitioner pulls up his/her hands rapidly. The area is sealed by placing two hands on top of each other over the treated area. Rependuling is done and the process repeated as necessary. If no further blockages, then repair of nerve damage can be done with laser and ultrasound, followed by unruffling. If muscles or joints need repair, ultrasound is used. Completion of the back technique concludes with a brushing of the aura. The spine is energized by the practitioner placing the left hand at the neck and the other at the base of the spine. This is held until balance is noted. Then, with the left hand in place on the neck, the right hand gently sweeps down and away off the back. The same techniques can be used with the neck except a more gentle touch is needed (Hover-Kramer, 1996; Mentgen \& Bulbrook, 1995).

15. Pain Drain - this technique is used to help alleviate pain. The practitioner places the left hand on the area of pain with the right hand lowered away as if draining something off. This position is held until the practitioner feels no further energy movement. The right hand is then placed on the area with the left hand elevated to receive energy to fill the void (Hover-Kramer, 1996; Mentgen \& Bulbrook, 1995).

16. Pain Ridge - is a ridge in the energy field from acute 
pain which may be $12-18$ inches to several feet away from the body. Unruffling aids in its removal ( Hover-Kramer, 1996; Mentgen \& Bulbrook, 1995).

17. Sealing a wound - a technique of gathering energy in the practitioners palms and placing over an area that was determined by assessing to have a tear, leak, or cold air column. These wounds occur after trauma, surgery, or childbirth (Hover-Kramer, 1996; Mentgen \& Bulbrook, 1995). 18. Chelation - is a technique of clearing out, filling and balancing the first four layers of the energy field. The practitioner's own energy vibration is higher than the person being worked on by the process of meditation. The practitioner places the thumbs on each hand on the ball of the foot in the center just below the metatarsal pad and chelating each. Next, one hand is placed on the left foot sole, and the other on the left ankle and chelation is done again. It is repeated with the other foot. The practitioner places the right hand on the left ankle and the left hand on the left knee, then chelates. This is repeated with the right leg. The right hand is placed on the left knee and the left hand is placed on the left hip, then chelates. This is repeated with the other leg. The practitioner replaces the hand on the right hip with the right hand and places the left hand over the sacral chakra, then chelates. The right hand then moves to the other hip, then chelates. The practitioner moves her right hand to over the root chakra 
while leaving her left hand over the sacral chakra, then chelates. The right hand moves to the sacral chakra and the left to the solar plexus chakra, then chelates. The right hand moves to the solar plexus, and the left to the heart chakra, then chelates. The right hand moves to the heart chakra, and the left to the throat or behind the neck, then chelates. The practitioner moves to the head of the table and places one hand on each shoulder and chelates. The hands on placed on the person's cheeks for slow chelation (Brennan, 1987; Bruyere, 1994; Mentgen \& Bulbrook, 1995). 19. Spinal Cleansing - is an additional back technique used if chelation does not clear or if a severe back problem exists. The practitioner locates the foramens in the sacrum and lightly massages them with the left hand turning counterclockwise and the right hand clockwise. Next, small spiral are continuously made moving up the spine coming off the head. Again, the left hand is spinning counterclockwise, and the right hand clockwise. The practitioner's hands are then cupped one on the other and placed over the sacrum. Larger, clockwise spirals are made moving up the spine and off the head. This sequence is repeated three times (Brennan, 1987; Mentgen \& Bulbrook, 1995). 20. Etheric Template (or 5 th level interventions) - are three techniques to clear and repair the 5 th level field. Etheric unruffling is a technique to clear and vitalize the etheric layer. It is done with the practitioner's hand 
combing the field upward as if running fingers through hair. This is continued until the layer is clear and smooth. Lymphatic Drain is done to flush the lymph system by altering energy flow in the etheric field. Each area is worked until smoothness is felt. The practitioner holds his/her hands with fingers spread and slightly flexed in a raking position. With short, rapid raking motion, the practitioner starts at the sternum pulling to him/her, under the arm, down the arm, and off the fingers. Repeat on the other side. Next, the same movements are used starting at the abdomen and pulled down and off the side, then through the groin, down the leg, and off the foot. This is repeated on the other side. The practitioner then moves to the person's head and uses the same raking motion on each side of the head. The person is turned over and the same procedure is done on the back. With Spiritual Surgery, the practitioner is passive and allows spirit guides to perform the work needed on the etheric field through the practitioner's body. The practitioner simply holds the space for the guides to work (Brennan, 1987; Mentgen \& Bulbrook, 1995) .

21. Celestial Body (or 6 th level intervention) - is another technique whereby spirit guides perform the work and the practitioner simply holds the space through higher energy vibration. The practitioner stands at the head of the person, forms a triangle of his/her hands with fingers over 
fingers, and thumbs overlapping each other to form a window in the middle. The hands are placed over the brow of the person and are raised intuitively to the outer edge of the sixth level. The spirit guides then come in to do their work. The practitioner is told intuitively when they are completed (Brennan, 1987; Mentgen \& Bulbrook, 1995). 22. Ketheric Template (or 7 th level intervention) - occurs immediately after 6 th level work whereby the practitioner extends his/her hands upward through the 7 th layer and sends golden light over the body. The hands are slowly moved around the body to form a circle. Once completed, the practitioner moves to the outside of the layer and touches the edge to maintain the light. The practitioner intuitively knows when to stop and gives a gesture of closure or prayer at the end (Brennan, 1987; Mentgen \& Bulbrook, 1995). 
Appendix B 
Information and Consent for Healing Touch Research

Charlene Christiano, R.N., Student of Florida International University School of Nursing, is doing research about the experience of Healing Touch on patients with cancer. As more people are exploring complement healing and health treatments, she is interested in finding out what cancer patients experience when receiving Healing Touch.

Healing Touch is a treatment whereby the Healing Touch practitioner uses the hands placed either on the body directly or off the body over a specific area in order to assist in the healing process. If you agree to participate, the researcher will contact you by phone or through your doctor's office or clinic within one week to arrange a time for the treatment. This study will use interviews and observations to obtain information about the experience of Healing Touch. There will also be questions about some personal information, such as age, sex, and education.

The treatment will be done in the cancer patient's home to allow a more natural response to the experience as well as to provide privacy and comfort. Space, about the size of a loveseat, should be available in the cancer patient's home to allow the practitioner enough room to provide the treatment. At the scheduled time of the treatment, the researcher will introduce the Healing Touch Practitioner to the cancer patient. After a brief introduction, the treatment will begin. One treatment will be given ranging in time from 5-60 minutes in length. The cancer patient will be interviewed immediately after the treatment and the interview will be audio recorded. After the information is collected and studied, it will be given back to you in written form, followed by a conversation between you and the researcher, to insure correctness. The entire time involved should be about three hours.

The exact outcome of the experience is unknown. This study may have some benefit to you physically, emotionally, mentally or spiritually. No harm is anticipated, but minimal stress and inconvenience may occur. Your willingness to participate is entirely up to you, and you may refuse to continue at any point in the study without any penalty.

All information obtained is confidential and will be seen only by the researcher. Any written information will be anonymous and the results grouped as a whole.

If you have any questions about the study, you should contact the researcher:

Name: Charlene Christiano, RN

Phone: (954)846-0832

or Supervising Faculty: Dr. Jacquelyn Hartley, PhD. Phone: $\quad(305) 919-5915$ 
Consent

Participant (Please Print Name)

I have read and/or had explained the above consent. I understand, and agree to be part of this study with knowing that I can refuse to answer any question or participate in any aspect of the treatment without penalty. I also understand that I can withdraw from the study at any time. This form has been signed in duplicate and I am keeping a copy for myself.

Signed:

Witness:

Date: 
Appendix C 
General Information Sheet: Healing Touch Practitioner Please fill out the following information:

1. Name:

2. Age:

3. Date of Birth:

4. Sex: (Check one) Male_ Eemale

5. Religion:

6. Highest level of formal nursing education:

7. Level of Healing Touch education:

8. Years practicing Healing Touch:

9. Experience using Healing Touch with cancer patients? Yes

No 
General Information Sheet: Cancer Patients

Please fill out the following information:

1. Name:

2. Age:

3. Date of Birth:

4. Sex: (Check one) Male

Eemale

5. Religion:

6. Highest level of education:

7. Type of cancer:

8. Cancer spread to other areas of the body? Yes

No

Location(s) of spread?

9. How long have you been diagnosed?

10. Current cancer treatment:

Chemotherapy

Radiation

Hormone

Surgery None

11. Previous cancer treatment:

Chemotherapy

Radiation

Hormone

Surgery

None

12. Are you currently taking pain medication? Yes No

13. Are you or have you used nonmedical treatments (such as vitamin therapy, chiropractic, massage, imagery, etc.)? Yes No

If so, which ones? 
Appendix D 
Healing Touch Method Used During the Encounter

Please place an "X" next to all methods used as well as if you use the method as taught or if you modified it.

Method

1. Therapeutic Touch

2. Chakra Connection

3. Ultrasound

4. Laser

5. Chakra Spread

sitting

lying down

6. Scudder Technique sitting

\section{lying down}

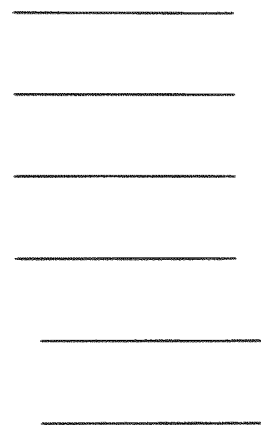

\section{As Taught Modified \\ As Taught Modified}
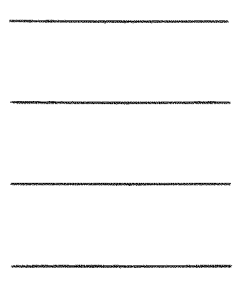

7. Mind Clearing sitting

$$
\text { lying down }
$$

8. Spiral Meditation

9. Back and neck Techniques

Lower body connection

Vertebral Spiral

Hopi Technique

10. Pain Drain

11. Pain Ridge

12. Sealing a Wound

13. Chelation

14. Spinal Cleansing
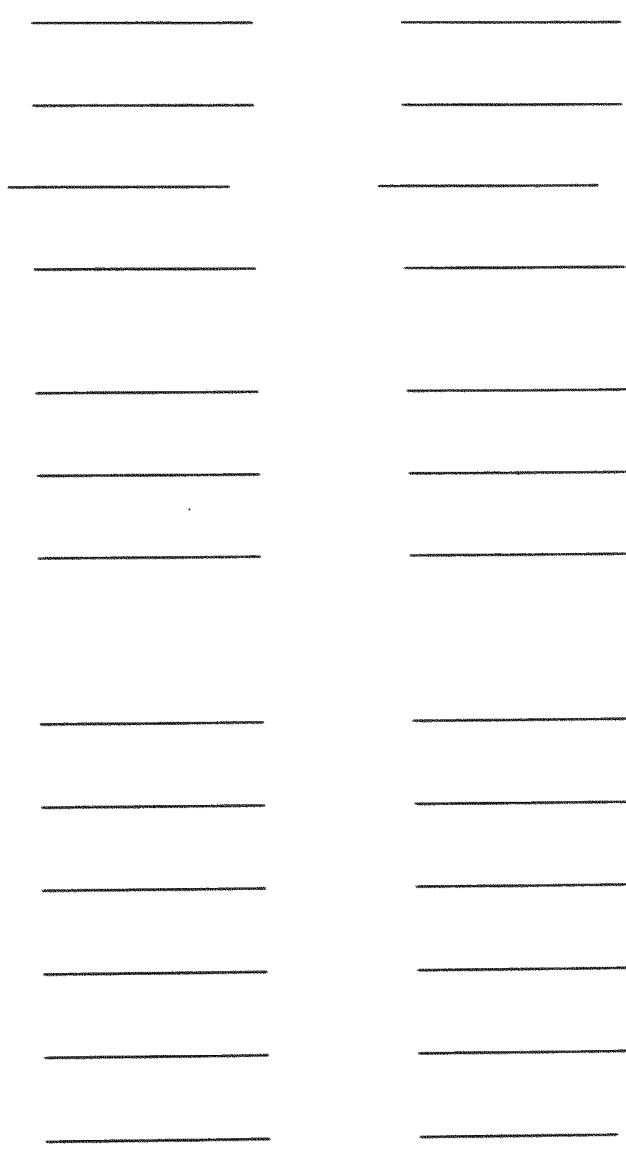
15. Etheric Template

Etheric Unruffing

Lymphatic Drain

Spiritual surgery

16. 6th level intervention

17. 7th level intervention

18. Comments: 